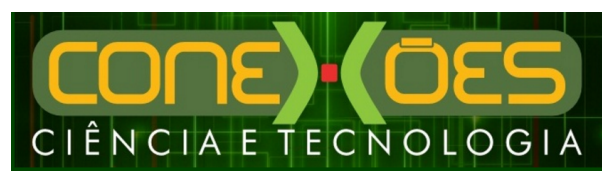

\title{
ÉTICA E MORAL: HÁ DIFERENÇA ENTRE A TEORIA E A PRÁTICA?
}

\author{
EMilia Suitberta De Oliveira Trigueiro ${ }^{1}$ \\ ${ }^{1}$ Instituto Federal de Educação, Ciência e Tecnologia do Ceará (IFCE) \\ <emiliatrigueiro@hotmail.com>
}

DOI: $10.21439 /$ conexoes.v12i3.1080

\begin{abstract}
Resumo. O presente artigo busca identificar qual é o entendimento que os servidores (docentes e técnicoadministrativos) de uma instituição pública de ensino têm sobre o conceito de ética e como se dá o comportamento moral dos mesmos no exercício da profissão. Para isso utilizou-se o Teste de Associação de Palavras e o Instrumento para Avaliar Comportamentos Morais nas Organizações. A pesquisa foi realizada por meio eletrônico com 44 servidores. Os principais resultados encontrados dizem respeito à discrepância entre a teoria e a prática desses servidores, pois eles, individualmente, manifestaram noções do que seria ética, no entanto, a organização como um todo, foi classificada em um nível de desenvolvimento organizacional pré-moral.
\end{abstract}

Palavras-chaves: Ética organizacional. Comportamento moral. Servidor público.

\section{ETHICS AND MORAL: ARE THERE DIFFERENCES BETWEEN THEORY AND PRACTICE?}

\begin{abstract}
This article aims at identifying what understanding public servants (both professors and employees) from a public institution of education have about the concept of ethics and how their own moral behavior occur during their professional practice. In order to do so, the Word Association Test and the Instrument to Evaluate Moral Behavior in Organizations. The research was developed through technological device with 44 servants. The main results found speak about the inconsistency between theory and practice of such servants since they individually demonstrate the principles of what ethics would be. However, the organization as a unit was classified as an organization of pre-moral development.
\end{abstract}

Keywords: Organizational Ethics. Moral behavior. Public servant.

\section{INTRODUÇÃO}

Ética e moral são temas de grande relevância para as organizações, sejam públicas ou privadas, visto que podem interferir no desempenho das mesmas. A ética individual nasce das experiências existenciais do indivíduo enquanto a ética profissional nasce da necessidade de satisfazer os interesses coletivos ao qual a atividade é destinada. Com isso a ética, individual ou profissional, é manifestada através das ações, ou seja, da moral. Assim, para que a organização tenha uma boa conduta, a ética e a moral profissional devem alinhar os preceitos teóricos do ofício, a satisfação do cliente e a felicidade do agente.
A moral, mais do que a ética, possui influência social na sua constituição. Essa influência se dá através dos valores culturais que são transmitidos de uma geração a outra. A cultura que é passada para nós brasileiros vem sendo construída há mais de 500 anos, e forma traços de comportamento que quando presentes nas organizações influem nas práticas dos integrantes e os levam a ações que podem contrariar seus ideais de ética. Nas organizações públicas se torna ainda mais necessário entender o comportamento dos servidores, visto que seus salários são custeados pelos impostos pagos por todos os brasileiros, inclusive por ele próprio.

Nesse contexto, o presente artigo objetiva mensu- 
rar e analisar o conceito de ética e o comportamento moral organizacional dos servidores (docente e técnicoadministrativos) de uma instituição pública de ensino. Para isso foi utilizado o Teste de Associação de Palavras tendo como estímulo indutor a palavra ética, e o Instrumento para Avaliar Comportamentos Morais nas Organizações, baseado em Licht (1996). Justifica-se a importância do mesmo pelo fato de o tema ser atual e relevante para a sociedade com um todo, já que estamos ligados a organizações desde o nosso nascimento até a nossa morte. Já em relação à instituição analisada, os resultados desta pesquisa podem ajudar na reflexão dos servidores sobre suas práticas profissionais.

$\mathrm{O}$ artigo estrutura-se em 5 partes. Após esta introdução aborda-se a ética e a moral no serviço público. $\mathrm{Na}$ terceira parte é especificado o percurso metodológico utilizado para desenvolver a pesquisa. A seguir há os resultados e discussões sobre eles, e por fim as conclusões e recomendações.

\section{2 ÉTICA E MORAL NO SERVIÇO PÚBLICO}

\subsection{Sobre ética e ética profissional}

A ética, do latim Ethica, é conceituada como "uma reflexão sobre o fazer, antes de fazer, procurando fazer bem" (Souza Filho, 1998, p. 27). Assim, quando, antes de praticar determinada ação, alguém se questiona subjetivamente sobre o sentido do comportamento que irá efetivar, estará, neste ato de questionar-se, consumando o momento ético. O objeto material da ética é o fato moral consumado, é o fazer, é o agir concreto, é a preocupação com a ação que ainda não foi efetuada. Já a ética profissional é conceituada pelo mesmo autor como sendo a reflexão pessoal do agente profissional, buscando definir diretrizes orientadoras de seu procedimento laboral. Tanto a ética pessoal quanto a ética profissional possuem como característica importante o caráter subjetivo de seu critério de verdade, que ressalta as lições existenciais transmitidas através da historicidade individual de cada sujeito.

Essa historicidade, presente em todas as dimensões da vida humana, exerce grande influência em todas elas, como por exemplo, na atuação profissional do indivíduo. As noções individuais de ética que o sujeito possui serão levadas para o campo profissional e influenciarão o seu fazer laboral junto com as normativas específicas da profissão. Segundo Souza Filho (1998), é inegável a influência da ética, orientadora da vida pessoal, na diretriz que o indivíduo imprimirá à sua profissão. Os valores relativos à honestidade, solidariedade humana, fraternidade e fidelidade a seu cliente provirão, geralmente, da experiência ética que o profissional já viven- ciou como indivíduo. No entanto, para que as ideias pessoais dos indivíduos não prevaleçam sobre os princípios profissionais, surgem códigos com normas estandardizadas e comprovadas pela prática social como sendo boas e eficazes. Esses códigos de normas são os Códigos de Ética regulamentadores das profissões.

Devido à sua grande relevância a ética profissional atualmente está sendo muito discutida em todas as esferas da sociedade. No entanto, quando pensa-se sobre a falta de ética profissional a atenção se desloca para a esfera pública, na qual o Estado e seus agentes são identificados como o principal foco de descomprometimento com valores éticos. No setor privado, o consumidor tem a possibilidade de não escolher uma determinada empresa por conta do seu comportamento não ético, no entanto, no setor público, as relações provedor/consumidor são mais complexas, pois não há muitas possibilidades de escolha e alguns serviços têm caráter compulsório. Assim, a clientela dos serviços públicos não se caracteriza pela liberdade de escolha, mas pelo fato de ser detentora de direitos e deveres inerentes à cidadania, o que faz com que os servidores públicos tenham o compromisso de bem servi-los (AMORIM. 2014).

Nesse sentido, viver eticamente nas organizações públicas constitui uma necessidade. Por isso os regimes jurídicos modernos impõem uma série de deveres aos servidores públicos como requisito para o bom desempenho de seus encargos e regular funcionamento dos serviços. A lei 8.112, de 11/12/1990, que instituiu o Regime Jurídico dos Servidores Públicos Civis da União, das Autarquias e das Fundações Públicas Federais, não utiliza expressamente o vocábulo ética, mas anuncia deveres, proibições, responsabilidades e penalidades que objetivam balizar a atuação dos servidores.

Já o Código de Ética Profissional do Servidor Público Civil do Poder Executivo Federal (Decreto $\mathrm{n}^{0} 1.171$, de 22/06/1994), teve por objetivo complementar e detalhar as condutas éticas dos servidores já presentes na Lei no 8.112. Em seu capítulo I, inciso I, o Código de Ética apresenta como regra deontológica para os servidores "primar pela dignidade, decoro, zelo, eficácia e consciência dos princípios morais, seja no exercício do cargo ou função, ou fora dele já que refletirá o exercício da vocação do próprio poder estatal". O inciso II trata mais especificamente sobre a conduta ética, mostrando que "o servidor não terá que decidir somente entre o legal e o ilegal, o justo e o injusto, o conveniente e o inconveniente, o oportuno e o inoportuno, mas principalmente entre o honesto e o desonesto".

Esses dois ordenamentos têm vários pontos em comum no que tange à prescrição de conduta adequada 
aos servidores públicos, que deve sempre ser norteada visando o bem comum e a moralidade do ato administrativo. Como o servidor público é ao mesmo tempo prestador e usuário do serviço exige-se dele um comportamento moral exemplar, já que seus atos, comportamentos e atitudes serão direcionados para a preservação da honra e da tradição do serviço público.

Com tudo que foi apresentado percebe-se a importância da ética nas organizações, principalmente nas públicas, visto que ela sustentará as relações entre a organização, os servidores e os beneficiários do serviço. Assim, sendo a ética fortemente influenciadora do comportamento moral, se faz necessária a análise deste e dos outros fatores que o influenciam.

\subsection{Sobre moral e comportamento moral organiza- cional}

A moral, do latim Moralia, é a consumação prática da ética. Souza Filho (1998) conceitua o fenômeno moral como um dado empírico que pode ser observável no comportamento humano: a ética positivada na ação humana concreta. Segundo o autor, dada a interiorização psicológica e subjetiva da ética, o que se pode ver é a moralidade, sua prática exterior, o comportamento concreto.

É importante pontuar também que a moral, como fato de vida social, é bem mais dinâmica do que a ética, que, por sua vez, é mais estática e conservadora. A moral se modifica e se altera com mais facilidade dada a sua exterioridade e superficialidade. A ética, por outro lado, é mais resistente às mudanças por ser um conjunto de valores, ideias e princípios sobre os quais o homem reflete para pensar a ação feliz e segura (Souza Filho. 1998).

Segundo Abbagnano (2007), a moral é a adaptação progressiva do homem às suas condições de vida. O que o indivíduo enxerga como dever ou obrigação moral é resultado de experiências repetidas e acumuladas através de inúmeras gerações, é o ensinamento que essas experiências propiciaram ao homem em sua tentativa de adaptar-se cada vez mais às suas condições vitais.

As normas de conduta que surgem dessas adaptações, além de plurais, são sociais, ou seja, precisam ser discutidas no interior da coletividade. A relação entre o indivíduo e a sociedade é de benefício mútuo porque as comunidades necessitam da contribuição de seus membros para sobreviver e progredir. A base sobre a qual a sociedade pode sobreviver é o fortalecimento do seu caráter comunitário, caráter este que só se estabelecerá se os indivíduos encarnarem determinados hábitos, necessários para desempenhar seu papel na comunidade, que serão reunidos em torno de uma ideia comum de

\section{bem.}

A sociedade tem interesse efetivo em padrões comportamentais que assegurem a paz e o equilíbrio da vida grupal e de suas instituições fundamentais. Isso nem sempre ocorre, pois o comportamento social é influenciado pela cultura em que a coletividade está inserida. A cultura é definida por Pires e Macêdo (2006 p. 84) como sendo "um conjunto de modos de pensar, de sentir e de agir, mais ou menos formalizados, os quais, tendo sido aprendidos e sendo partilhados por uma pluralidade de pessoas, servem de maneira ao mesmo tempo objetiva e simbólica, e passam a integrar essas pessoas em uma coletividade distinta de outras". Os autores relatam que a cultura é um dos pontos chave na compreensão das ações humanas e das coletividades, como, por exemplo, as organizações e os países.

Para entender a substância empírica das coletividades, deve-se lembrar que os participantes da organização, além de representarem suas próprias organizações, são portadores de vários estatutos, como classe social e categorias sociais, incluindo-se nestas gênero, raça, etnia, geração, religião, preferência sexual, estado civil, entre outros, e são também representantes de uma cultura nacional, regional, local e organizacional. Assim, os valores que os indivíduos têm ao ingressar no mundo do trabalho influenciam definitivamente suas ações, podendo refletir inclusive no seu nível geral de produtividade. Sabendo que existe uma relação direta entre a performance de uma organização e sua cultura, e que esta cultura organizacional carrega muito da nossa cultura nacional, faz-se necessário conhecer um pouco das nossas raízes culturais, para melhor entender a cultura organizacional.

Segundo Freitas (2006), para bem entender as organizações brasileiras, devem ser entendidos os traços gerais de nossa cultura, que começou a ser formada há mais de 500 anos. Esses traços brasileiros, características gerais comuns ou frequentes na maioria dos indivíduos, são parte do inconsciente de todos nós e foram constituídos historicamente, como pode ser percebido. A formação da sociedade brasileira foi híbrida, formada pelo "triângulo racial" entre brancos, negros e índios, o que levou à criação de alguns traços muito presentes na sociedade, entre eles: hierarquia, personalismo, malandragem, sensualismo, aventura.

Esses traços brasileiros formam algumas figuras presentes na sociedade e nas organizações. São elas: cunhados, coronéis, homens cordiais, malandros, jeitosos e despachantes. Segundo Machado (2008), essas imagens interiorizadas pelos indivíduos estão presentes no imaginário social e no imaginário organizacional, mas, como indivíduos ou como pessoas, não têm 
existência real nas organizações.

Srour (2005) cita que essa cultura brasileira formou dois códigos de conduta, duas morais que abrangem toda população. Estes códigos não se comunicam, pois guardam conteúdos qualitativamente distintos e opostos. O primeiro código é o da moral da integridade, que confronta um código de natureza altruísta e inclusiva, que orienta as pessoas a terem "caráter", a serem decentes e "de bem". Como primeira moral, oficial e pública, é ensinada nas escolas e igrejas. O segundo código é o da moral do oportunismo, de natureza egoísta e excludente, que orienta as pessoas a serem malandras, a "levar vantagem em tudo", sem se importar com as consequências sobre os outros. Como segunda moral, é difundida à boca pequena pelos íntimos e faz apologia à esperteza, justificando os muitos "jeitinhos", as ações entre amigos, os arranjos paralegais e as práticas dissimuladas. Essa duplicidade moral permite que costumes tipificados como imorais pelos cânones públicos da integridade sejam considerados socialmente aceitáveis do ponto de vista privado.

Essa cultura brasileira assume papel de destaque no comportamento das organizações à medida que influi no modo de vida, nos padrões e nos valores das pessoas que, durante a maior parte do tempo, se dedicam a elas e para onde transportam não apenas seus conhecimentos técnicos, mas também todas as características de suas personalidades. A cultura organizacional na esfera pública possui peculiaridades promissoras de análise devido ao fato de ser organizada mediante um conjunto de regras de caráter impessoal, o que, de certa forma, delimita formalmente o espaço organizacional (SARAIVA. 2002). No entanto, muitas vezes os servidores públicos sentem-se desprovidos de referenciais éticos o que os leva a criar suas próprias normas de conduta como forma de se adaptarem à cultura em que estão inseridos. Esse processo de adaptação à novos padrões morais é sempre digno de interesse, e merece aprofundamento.

\subsection{Sobre o desenvolvimento do comportamento moral organizacional}

Quando nascemos já encontramos um mundo feito e definido: uma sociedade real que não ajudamos a construir, com suas contradições, mazelas e vantagens, e também com uma ética oficial imposta aos indivíduos. Da mesma forma que a mãe vacina o bebê recémnascido contra algumas doenças que podem comprometer a saúde do seu filho, a sociedade, através de suas agências institucionais de controle, também administra na criança algumas "vacinas éticas" destinadas à preparação de um comportamento social eficaz e estável (Souza Filho, 1998).
A maneira como esses conceitos se desenvolvem no individuo é tópico de grande interesse para a filosofia, para a psicologia, para a sociologia e para a educação. A questão que nos norteará nesse momento é a seguinte: como é que o ser humano transforma-se numa pessoa que respeita os outros e a sociedade se nasceu uma criança sem princípios morais?

Na psicologia, em particular, diversas correntes teóricas têm abordado a moralidade sob diferentes aspectos. A psicanálise explica a origem da moralidade através do "Complexo de Édipo", no qual a criança, para livrar-se da ansiedade causada pelos desejos em relação ao pai ou a mãe, imagina-se no lugar dele/dela e incorpora as regras a partir da proibição do incesto, generalizando para outras regras morais da sociedade. Psicólogos behavioristas, por sua vez, consideram a moralidade como um fenômeno de resistência à extinção. A criança é punida tantas vezes por um comportamento indesejável, que a punição torna-se desnecessária e o comportamento desaparece mesmo na ausência da punição, o mesmo acontecendo com o comportamento desejável, que é reforçado positivamente até se estabelecer. O sócio-interacionismo enfatiza o papel do sujeito humano como agente do processo moral, focalizando não tanto o sentimento de culpa ou o real comportamento moral, mas o julgamento moral, o conhecimento do certo e do errado, o que a pessoa acha ou julga como certo ou errado (BIAGGIO, 2006).

Esse processo de desenvolvimento de comportamentos morais adequados também ocorre nas organizações. Partindo dos conceitos sócio-interacionistas, Petrick e Wagley (1992) criaram um modelo de desenvolvimento moral aplicado às organizações baseado em três estágios e seis níveis morais. Esse modelo preocupa-se com a cultura moral que predomina em uma organização através dos comportamentos morais mais frequentes emitidos pelos indivíduos que nela atuam.

O primeiro estágio no Modelo de Desenvolvimento Moral Organizacional é denominado sobrevivência maquiavélica, pois o ambiente de trabalho caracteriza-se pela troca de favores e pela manipulação para atingir objetivos pessoais, e não os institucionais. Esse estágio é composto por dois níveis. O primeiro é denominado "darwinismo social", pois o receio da extinção e a urgência de sobreviver financeiramente ditam a conduta moral da instituição e o emprego direto da força é a norma aceita para obter os resultados pessoais esperados. O segundo nível deste estágio é denominado "maquiavelism", pois os ganhos da organização guiam suas ações.

O segundo estágio é denominado autoridade e con- 
formidade, pois há, na organização, respeito pela autoridade e conformação aos padrões sociais predominantes. O primeiro nível desse estágio é o da "conformidad”, pois há uma tradição de procedimentos operacionais padronizados e a pressão dos pares para aderir às normas sociais dita o que é comportamento certo ou errado. A burocracia e o paternalismo são procedimentos comuns nesse nível. O quarto nível é o da "lealdade para com a autoridade", pois as direções de uma autoridade legítima denominam os padrões morais da organização.

O estágio mais elevado de desenvolvimento moral é denominado organização e integridade, pois a participação na tomada de decisões e a confiança nas regras da maioria se tornam padrões morais da organização. Esse estágio compõe-se dos dois últimos níveis. O quinto é o da "participação democrátic", pois há, na organização, grande tolerância para a diversidade que se integra no esforço de integração dialética. Neste nível, o voto individual da maioria determina políticas e procedimentos. O ultimo nível é o da "integridade baseada em princípios", pois a justiça e os direitos individuais são os ideais morais. O julgamento equilibrado entre interesses conflitivos forma o caráter da organização, o que, por seu turno, determina os comportamentos corretos ou incorretos (PETRICK; WAGLEY, 1992). Esses estágios e níveis podem ser melhor visualizados na Figura 1

Como pôde ser percebido, a moralidade é construída na sociedade e à ela serve através da manutenção dos contratos sociais. A moralidade não é imposta ao indivíduo. Pais, professores, orientadores espirituais, lideres comunitários e políticos apenas fornecerão a base sob a qual o julgamento moral individual se construirá. Esse comportamento moral, por sua vez, apresentar-seá nos mais diversos contextos, como familiar, escolar e profissional, tendo, em cada um deles, suas especificidades.

Por ser um tema complexo, merece atenção e estudos aprofundados que visem propiciar conhecimento aos servidores e guiar sua prática profissional, objetivando otimizar o serviço desempenhado por eles. Nesse contexto insere-se a presente pesquisa que buscará compreender como os servidores públicos de uma instituição de ensino entendem a ética e suas relações com a moral. Para isso utilizou-se dos procedimentos metodológicos de coleta e análise que serão tratados no tópico seguinte.

\section{PERCURSO METODOLÓGICO}

A presente pesquisa é de natureza descritiva quanto aos objetivos, segundo Lakatos e Marconi (2001), e visa estudar, observar e analisar as características de um grupo. A mesma desenvolveu-se por meio de um estudo de caso com os servidores docentes e técnicoadministrativos de uma instituição pública de ensino básico, técnico e tecnológico, localizada no interior do estado do Ceará.

O procedimento de coleta de dados foi feito através do meio eletrônico com um questionário enviado por email para uma lista onde estão inseridos os endereços eletrônicos de todos os servidores da instituição. No corpo do texto do e-mail foi explicada, de forma sucinta, a natureza e a importância da pesquisa e foi solicitada a colaboração dos mesmos. Obteve-se a resposta de 44 servidores, o que corresponde a $24,7 \%$ do total, sendo 20 deles docentes e 24 técnico-administrativos.

$\mathrm{O}$ instrumento de coleta de dados foi composto por três partes. Na primeira parte consta um questionário socioeconômico que indaga acerca da idade, do tempo de serviço na instituição, da formação e do cargo que o servidor ocupa. Na segunda parte foi feito um Teste de Associação de Palavras, que constitui um tipo de investigação aberta que se estrutura na evocação das respostas com base em um estímulo indutor, que foi analisado segundo a teoria de Bardin (2011). Como estímulo indutor foi utilizada a palavra "ética". Para isso, foi solicitado que cada servidor escrevesse as três primeiras palavras que viessem à sua cabeça ao ler aquela palavra. Este teste teve por objetivo analisar o conceito de ética desses servidores.

$\mathrm{Na}$ terceira parte foi utilizado o Instrumento Para Avaliar Comportamentos Morais nas Organizações, adaptado de Licht (1996). O instrumento baseia-se na teoria do Desenvolvimento Moral Organizacional de Petrick e Wagley (1992) e na classificação em três estágios e seis níveis de desenvolvimento moral feita por eles.

O instrumento original é composto de 72 indicadores em forma de perguntas a serem respondidas com SIM ou NÃO, onde o sim significa que aquele comportamento ocorre na organização. As perguntas seguem o seguinte padrão: "Há organizações em que funcionários são deslocados de suas funções para fazer serviços pessoais para seus chefes. Isso também ocorre na sua organização? ( ) Sim ( ) Não”. Os indicadores correspondem aos seis níveis de desenvolvimento moral e para o presente estudo foram escolhidos 30 indicadores segundo conveniência e melhor adequação ao lócus da pesquisa. Cada nível de desenvolvimento moral está representado por cinco indicadores que aparecem listados em ordem aleatória, baseada em sorteio. Após a resposta dos servidores, as respostas afirmativas de cada pergunta foram reordenadas segundo o nível de desen- 


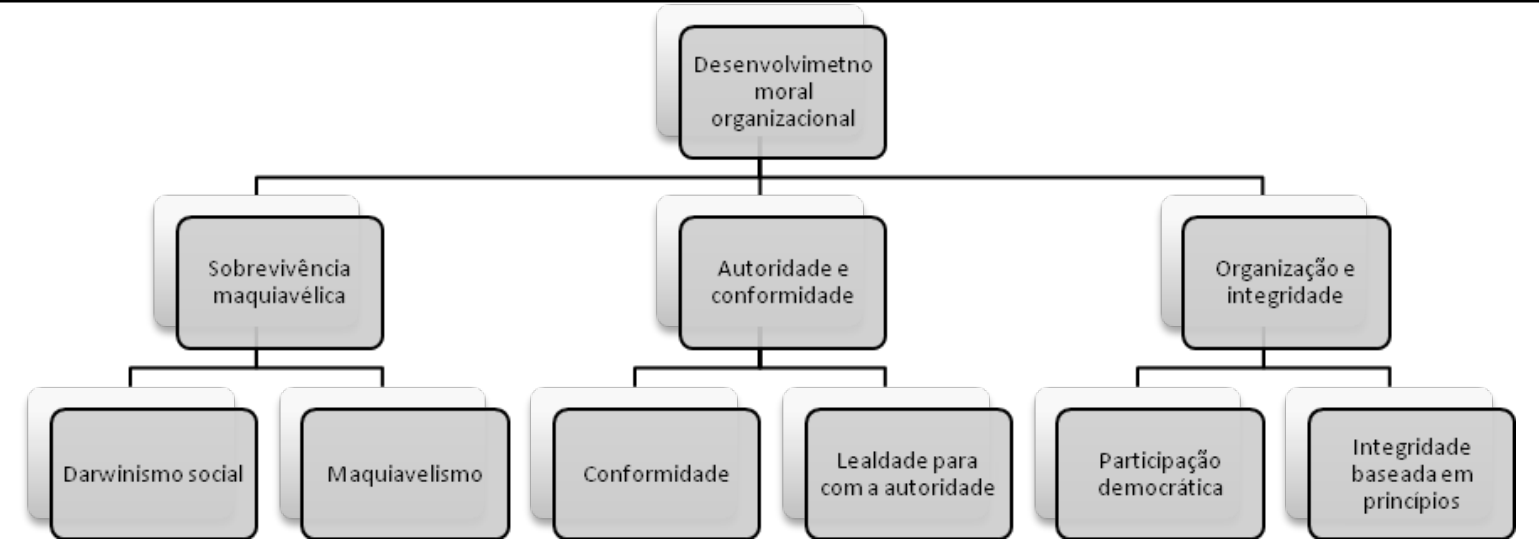

Figura 1: Modelo de desenvolvimento moral organizacional. Fonte: Do Autor (2018), baseado em Petrick e Wagley (1992).

volvimento moral, para que pudessem ser colocadas em termos percentuais que indicariam em qual estágio está a maior parte dos comportamentos presentes na organização.

Para a avaliação das respostas fornecidas foi empregada a técnica de distribuição de frequências e a medida de posição denominada moda, em que as respostas são agrupadas segundo os níveis morais e a porcentagem de respostas afirmativas mais frequentes em todos os questionários indica em que nível de desenvolvimento moral encontra-se a organização. Para um melhor detalhamento dos procedimentos conferir Trigueiro (2012).

\section{RESULTADOS E DISCUSSÕES}

A amostra deste estudo, composta por 44 servidores, tem as seguintes características: 22 mulheres e 22 homens; 5 tem idade até 25 anos, 10 tem idade entre 25 e 35 anos, 28 tem idade entre 35 e 55 anos e 1 tem idade acima de 55 anos. Quanto ao tempo de serviço dos pesquisados na instituição, 20 têm até 3 anos, 3 tem entre 3 e 10 anos, 16 tem entre 10 e 20 anos e 5 tem mais de 20 anos de trabalho na instituição. O grau de escolarização de 2 deles é ensino médio, de 3 deles ensino superior, 19 especialização e 20 mestrado ou doutorado. Quanto aos cargos efetivos dos sujeitos da pesquisa 20 deles são docentes e 24 são técnico-administrativos.

Quando questionados sobre as palavras que lhe vinham à cabeça ao ler a palavra ética, os servidores citaram as seguintes: atitude, caráter, idoneidade, respeito, trabalho, educação, verdade, justiça, moral, boa convivência, responsabilidade, compromisso, valores, paciência, honestidade, competência, sinceridade, bem, integridade, zelo pela coisa pública, impessoalidade, sigilo, conduta, prática, princípios, correto, pessoas, transparência, democracia, bom comportamento, con- fiável, prudente, dignidade, lisura, profissionalismo, decência, coerência, imparcialidade, diálogo, compreensão, consideração e seriedade.

A palavra mais citada foi respeito. Com isso, podemos supor que, para este grupo de servidores, respeito é a palavra que melhor define o que é ética. Pode-se inferir também que a alta frequência desta palavra pode estar relacionada à ausência deste na instituição. Já as palavras que foram citadas apenas uma vez foram as seguintes: atitude, boa convivência, paciência, competência, bem, zelo pela coisa pública, impessoalidade, prática, pessoas, transparência, democracia, prudente, dignidade, lisura, decência, coerência, imparcialidade, diálogo, compreensão, consideração e seriedade. Essas palavras são consideradas como não correspondendo ao conceito de todos os servidores, mas à opinião pessoal destes respondentes.

A Figura 2 demonstra a frequência com que essas palavras apareceram.

Essas palavras foram agrupadas e categorizadas levando em conta os critérios temático e léxico, classificando-as de acordo com seu sentido, emparelhamento de sinônimos e sentidos próximos, como orienta (BARDIN, 2011).

As palavras citadas levaram à formação de três categorias. A primeira delas contém as palavras que mais se aproximaram do conceito reflexivo da ética, e são as seguintes: verdade, honestidade, sinceridade, impessoalidade, sigilo, transparência, confiável, coerência, imparcialidade, compreensão, responsabilidade, compromisso, correto, prudente, diálogo, paciência, caráter, idoneidade, valores, integridade, princípios, dignidade, lisura, educação, decência, justiça, democracia, respeito, zelo pela coisa pública e moral. A segunda categoria contém palavras que estão relacionadas ao agir 


\section{- Número de citações}

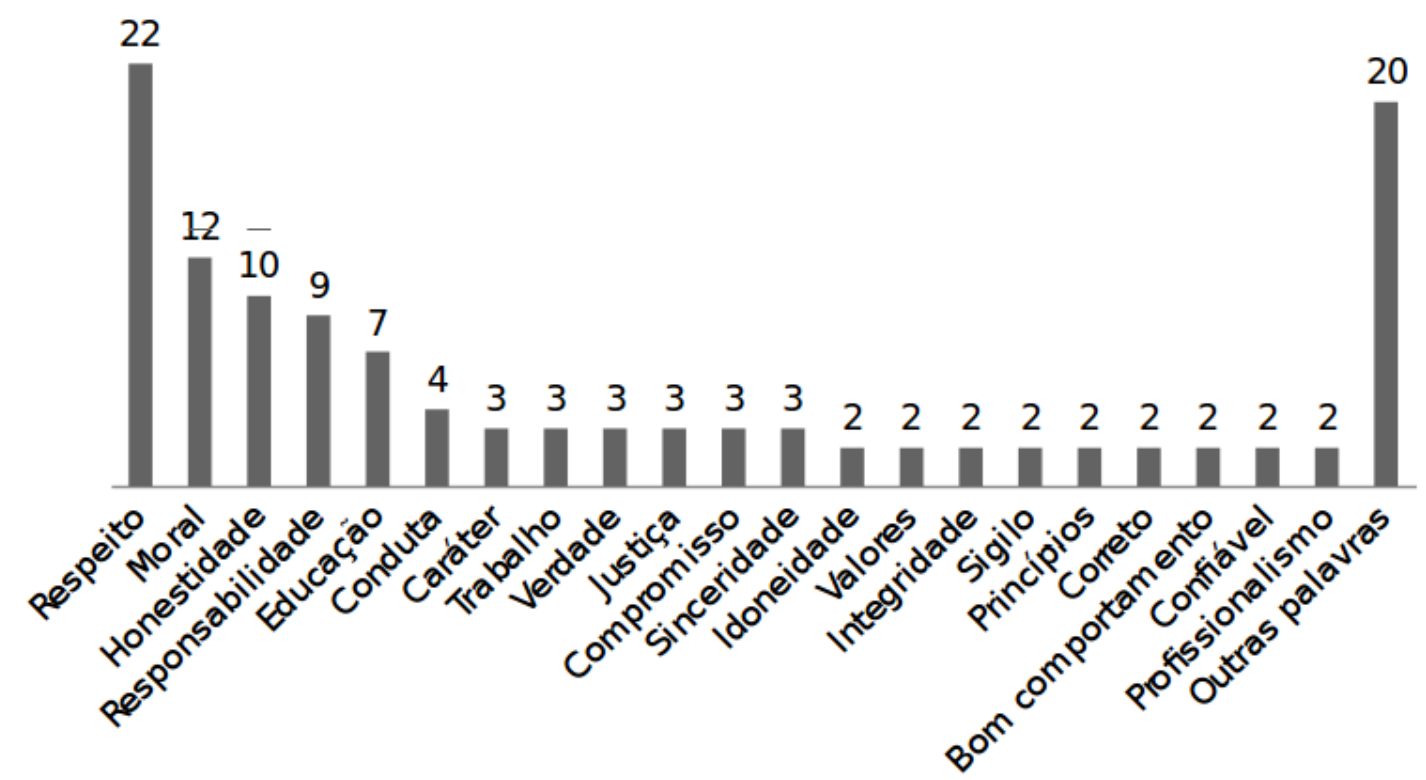

Figura 2: Número de vezes que cada palavra foi citada. Fonte: Do Autor (2018)

concreto, como atitude, conduta, prática, bom comportamento, trabalho, competência e profissionalismo, e estão mais relacionadas à moral, que é a consumação prática da ética. A última categoria diz respeito às consequências do comportamento ético, e contém as palavras boa convivência, bem, pessoas, consideração.

Mesmo a palavra ética não sendo associada à ética profissional, várias palavras relacionadas ao trabalho foram citadas pelos servidores. São elas: trabalho, responsabilidade, compromisso, honestidade, competência, zelo pela coisa pública, impessoalidade, sigilo, conduta, prática, pessoas, democracia, profissionalismo, imparcialidade. Pode-se inferir que isso deve-se ao fato de os pesquisados estarem inseridos em uma instituição, local onde sua ética deveria se manifestar.

Para inferirmos sobre a ética organizacional desses servidores analisaremos o comportamento moral dos mesmos. Para isso, na segunda parte da pesquisa, foi aplicado o Instrumento Para Avaliar Comportamentos Morais nas Organizações, que avalia o nível de desenvolvimento moral organizacional.

$\mathrm{O}$ instrumento foi analisado utilizando como base a teoria de Petrick e Wagley (1992), que propõe um modelo de desenvolvimento moral aplicado às organizações baseado em três estágios e seis níveis morais. Nas organizações, os indivíduos podem manifestar comportamentos típicos de cada um dos seis níveis.

Após a coleta das respostas dos servidores ao Instru- mento para Avaliar Comportamentos Morais nas Organizações, os indicadores utilizados nas perguntas, que estavam em ordem aleatória, foram reorganizados segundo o nível de desenvolvimento moral. As respostas afirmativas a cada pergunta foram contabilizadas e colocadas em termos percentuais. Essa porcentagem indica onde está a maior parte dos comportamentos presentes na organização e em qual nível dentro deste estágio, o que pode ser percebido na Figura 3

De acordo com os resultados desta pesquisa, a cultura moral modal da organização corresponde ao primeiro estágio de desenvolvimento moral organizacional, denominado pré-moral ou pré-convencional, no qual o comportamento moral do indivíduo é caracterizado pela troca de favores e pela manipulação para atingir objetivos pessoais, e não institucionais. As pessoas que pertencem a esse estágio possuem características como dependência, exploração, desconfiança, crença de que o outro é o problema, pretensão de grandes resultados com pequenos esforços e sensação que a vergonha é pior que o remorso. Nesse estágio as pessoas normalmente se comportam de forma a manter a obediência e respeitar as estruturas de poder para evitar a punição, e a referência do que está certo ou errado depende das consequências práticas das ações (LICHT, 1996).

Licht (1996) também afirma que esse estágio prémoral é composto por dois níveis. O primeiro nível, "darwinismo social", demonstra o receio da extinção e 


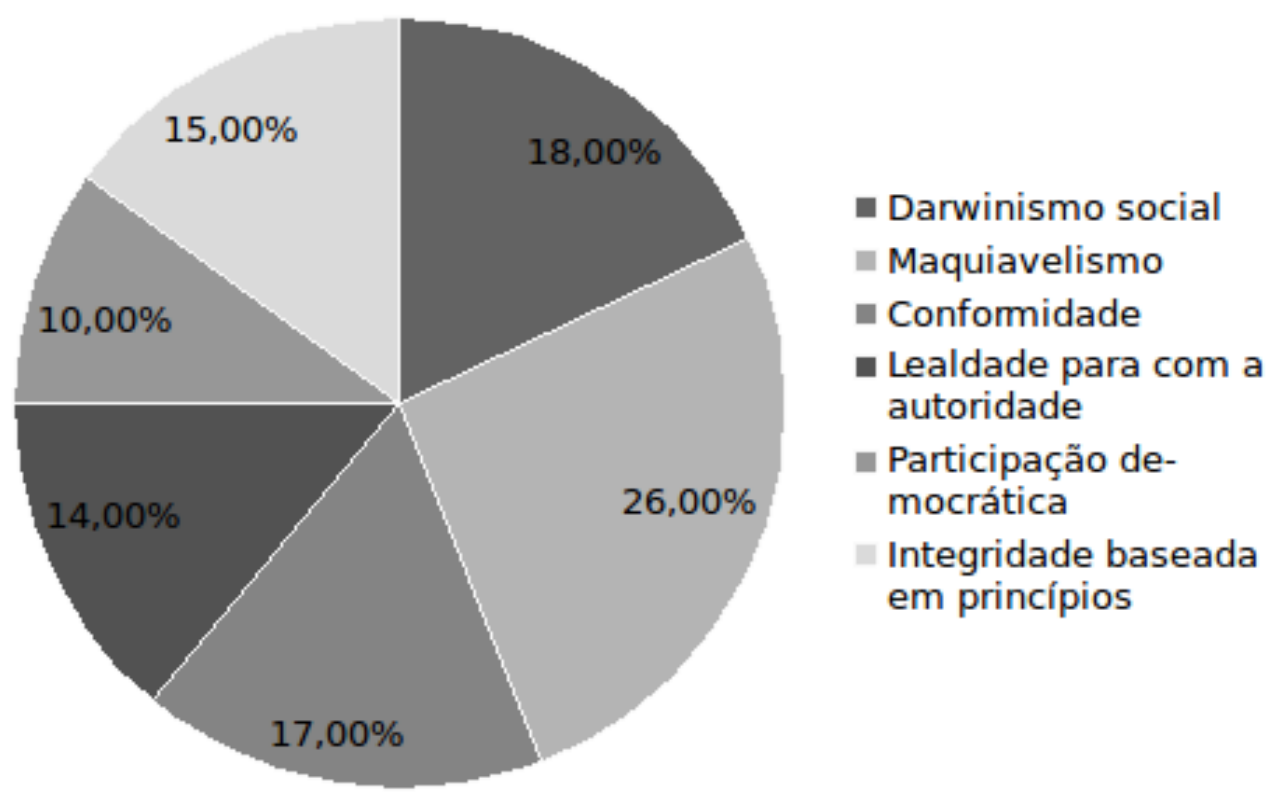

Figura 3: Nível de desenvolvimento moral organizacional Fonte: Do Autor (2018).

a urgência em sobreviver financeiramente, permitindo que somente os mais aptos sobrevivam. Esse nível tem como metáfora um leão que reina através da força. No nível 2, "maquiavelism", que foi o mais prevalente nos resultados, atingir os objetivos justifica a utilização de qualquer meio, o que coloca a desonestidade como uma conduta rotineira para a organização poder crescer. A raposa, astuta, traiçoeira, dissimulada e que ataca pelas costas, é a metáfora desse nível, onde busca-se agir para satisfazer a necessidades e interesses pessoais e deixar os outros fazerem o mesmo. Cita-se como exemplo de raciocínio das pessoas desse nível: "Eu vou ajudá-lo porque você pode retribuir ajudando também". Em organizações que operam nesse nível, a estratégia empregada pelos funcionários para conseguir avançar é pisar uns sobre os outros, e a atmosfera de desconfiança que vai se criando dificulta qualquer atividade que exija colaboração.

Um comportamento organizacional pouco desenvolvido, como o apresentado nesses resultados, tem consequências para a sociedade, pois forja um clima de cumplicidade e faz prosperar a impunidade e o oportunismo. Licht (2007) citam situações cotidianas de uma sociedade baseada no "e": pessoas que apresentam zelo e cuidados com a limpeza e organização de sua casa, porém agem de maneira desleixada em ambientes compartilhados com os demais (áreas de café e banheiros); pessoas que promovem reuniões barulhentas em edifícios, sem respeitar os horários estabelecidos para isso, acreditando que, por estarem em suas casas, podem fazer o que bem entenderem; pessoas que jogam lixo no chão com o intuito de assegurar o emprego de funcionários que são contratados para o serviço de limpeza pública; pessoas que reclamam e reivindicam quando recebem troco menor do que deveriam, porém se calam quando recebem troco maior.

Esses exemplos são comumente observados na nossa sociedade e podem revelar claramente o nível de desenvolvimento moral dos indivíduos. No entanto, não se pode afirmar que essas pessoas agem assim propositadamente para prejudicar o próximo, pois esses comportamentos são fruto da cultura do nosso país. O triangulo racial que nos formou deixou características como o personalismo, o "cunhadismo", a cordialidade, o coronelismo, a hierarquia, o jeitinho, entre outras. Esses traços brasileiros entram nas organizações e nelas deixam suas marcas, pois foram interiorizados pelos indivíduos e estão presentes no imaginário social e no imaginário organizacional, como nos diz Vasconcellos (1995).

Machado (2008) nos remete às figuras dos cunhados, coronéis, homens cordiais, malandros e padrinhos, que são fundamentais no ingresso em uma organização, já que o brasileiro sabe muito bem que em nossa sociedade personalista o que vale mais é a teia de relações. Todas essas figuras apontam para a prevalência de relações de subordinação e dependência, que permanecem intocadas num mundo que funciona nos moldes 
ÉTICA E MORAL: HÁ DIFERENÇA ENTRE A TEORIA E A PRÁTICA?

de uma grande família patriarcal com compadres, comadres, padrinhos e afilhados. Esta família patriarcal é guiada pela moral do oportunismo, que nos ensina a levar vantagem em tudo sem preocupação com as consequências.

Segundo Srour (2005), isso se deve a uma cultura cívica pouco desenvolvida, fruto de uma fragilidade institucional e de uma tímida cooperação coletiva. Essa duplicidade moral permite que determinadas ações sejam proibidas quando praticadas em público, mas aceitáveis na vida privada. Podemos inferir que, segundo esta lógica, os indivíduos saberiam o que é correto e incorreto, o que é ético e o que não é, mas nem sempre colocam em prática em sua organização.

Sabe-se que a cultura organizacional, que carrega os padrões morais presentes na coletividade, influencia diretamente na conduta dos indivíduos. Nesse sentido, Mendes et al. (2010) afirmam que as lideranças dos níveis hierárquicos superiores devem ser responsáveis pela manutenção de uma cultura que enfatize cotidianamente a importância da conduta ética para todos os funcionários, incorporando os valores éticos às políticas e regras.

Isso deve ocorrer porque a cultura da organização influencia diretamente nos seus resultados. Isso pode ser observado no estudo de Patias e Minho (2012), que analisou a influência da cultura organizacional na prestação de serviços públicos e concluiu que a cultura do órgão pesquisado por eles está abaixo do esperado. Isso se expressa da seguinte forma: os servidores dessa instituição manifestam falta de expectativas na carreira púbica, que impõe a eles a inércia de não querer competir, a geração de um ambiente neutro, onde nem os pontos positivos são valorizados e os negativos não são trabalhados ou punidos. Os autores perceberam que o ambiente organizacional não está favorável para o trabalho e que a cultura organizacional está influenciando negativamente no cumprimento de suas atribuições, prestação de serviços e na motivação dos servidores. Esse fato é tão importante que eles pontuam ainda que por ser uma estrutura rígida e não aderente ao novo, se mantiver esta forma de gestão, esta cultura organizacional poderá prejudicar ainda mais seu desenvolvimento, prejudicando os servidores que são desvalorizados, não realizando suas funções corretamente e prestando serviços aos usuários sem a qualidade esperada por eles.

Para Licht (1996), a mudança na cultura de uma organização é um processo complexo, pois a instituição carrega em sua cultura sua proteção e estabilidade, o que se reflete nas atitudes e comportamentos das pessoas. Esses comportamentos morais são manifestações que possuem razões bem mais profundas e que deixam consequências na prática das relações de negócios e interpessoais, e, portanto, não podem ser negligenciadas. Segundo o mesmo autor, as organizações deveriam adequar suas práticas administrativas para estar no terceiro estágio de desenvolvimento moral organizacional, seja no nível "participação democrátic" ou no nível "integridade baseada em princípio", pois, quanto maior o estágio moral da organização, maior a garantia de que os direitos morais coletivos são levados em consideração.

Segundo Carbone (2000), existem características na organização pública que dificultam a sua mudança, são as seguintes: burocratismo, excessivo controle de procedimentos, autoritarismo, centralização, excessiva verticalização da estrutura hierárquica, centralização do processo decisório, obter vantagens nos negócios do Estado. Segundo o mesmo autor os fatores que poderiam alavancam a mudança seriam: flexibilidade, mutabilidade, boa convivência intercultural, harmonização das diferenças.

De acordo com Carneiro (1998) o servidor público encontra-se desprovido de orientações a respeito de conduta ética, o que leva as coletividades a construírem suas próprias regras voltadas mais para interesses próprios do que para os da organização. Para reverter essa situação seria necessário um trabalho pedagógico de esclarecimento e persuasão utilizando medidas de cunho prático e ações efetivas.

Esse pensamento é corroborado por Patias e Minho (2012), que afirmam que a principal causa da resistência à mudança na administração pública está nas pessoas, que sofrem as influências da cultura organizacional, estando presas às formas antigas de desenvolver suas atividades, vendo no novo uma ameaça ao seu status quo. Um fator que pode levar uma organização a ser resistente ao novo e seguir realizando tarefas do mesmo modo que sempre fez é a sua cultura, por que ela influencia diretamente os servidores na sua maneira de pensar, agir ou até mesmo realizar uma tarefa. Isso pode ter como consequência o fato de que em uma organização não flexível a mudanças, mesmo que o servidor tenha uma forma correta de realizar a tarefa, sua cultura não é passada para a organização, por outro lado, a cultura da organização é passada para o indivíduo e é ele quem deve se adaptar ao ambiente em que está inserido.

o entanto, para que a vida em uma organização não seja guiada por interesses particulares, surgem os códigos de conduta profissional, que devem estar em consonância com os princípios éticos universais. O Código de Ética do Servidor Público (BRASIL, 1994) foi criado com o intuito de guiar os servidores para o bom desempenho de seus encargos e serviços. Pela presente pesquisa, no entanto, percebemos que o compor- 
tamento moral organizacional dos servidores da instituição não está em sintonia com o que é preconizado no referido decreto, já que eles responderam afirmativamente a questões que estão localizadas no estágio de desenvolvimento pré-moral ou pré-convencional, que, por sua vez, contrariam os princípios legais.

Com tudo isso, é possível perceber que os servidores da instituição pesquisada, individualmente, possuem clara noção do que seria ética, visto que $97 \%$ das respostas condizem com a ética e com a moral, que seu conceito sobre ela possui consistência teórica de acordo com o que foi colocado pelos autores estudados e que esse conceito é condizente com o que o Código de Ética do Servidor preconiza. No entanto, a organização como um todo está classificada no nível de desenvolvimento organizacional pré-moral ou pré-convencional, com $44 \%$ das respostas, e não no nível pós-moral ou organização e integridade, que seria o nível desejado, que está apenas com $25 \%$ das respostas.

Isso nos permite inferir que o indivíduo, em muitas circunstâncias, não realiza, na sua ação moral concreta, os fundamentos éticos que possui, visto que a coletividade na qual ele está inserido tende a desenvolver um código de conduta próprio que influencia o comportamento de todos. Ou seja, esse indivíduo contraria o que Souza Filho (1998) coloca como ética, que é ter consciência do seu dever e responder por isso em termos de conduta exteriorizada e atitude mental.

\section{CONCLUSÕES E RECOMENDAÇÕES}

Pelo presente estudo podemos concluir que esses servidores individualmente, possuem noções de ética, mas coletivamente o comportamento dos mesmos está classificado no nível pré-moral de desenvolvimento organizacional, o que mostra uma discrepância entre a teoria e a prática. Esse comportamento pode se manifestar em diversos contextos, no entanto, no contexto organizacional, tem graves implicações.

Não se pode afirmar que este é o comportamento de todos os servidores públicos, pois trata-se de um estudo de caso, o que dificulta a generalização. Da mesma forma, não se pode afirmar também que esse é o comportamento de todos os servidores desta organização, pois pode haver variação entre setores. No entanto, os resultados encontrados na presente pesquisa poderão proporcionar melhores possibilidades de reflexão para a organização, levando-a a compreender sua situação e refletir sobre a necessidade de dar outros rumos à sua forma de conduzir os negócios. Entre os cuidados que devem ser adotados, está o de evitar a rotulação da instituição e não acusar ou culpar os indivíduos a partir desses resultados, mas é benéfico ter ciência dos aspec- tos organizacionais mais vulneráveis para que se possa melhor desenvolvê-los.

Como citado anteriormente pelos diversos autores, uma mudança efetiva na organização só ocorrerá com um trabalho pedagógico que enfatize a importância da conduta ética. Para que isso ocorra nesta instituição, recomenda-se, inicialmente, a criação de uma Comissão de Ética Setorial que se encarregará de prevenir condutas incompatíveis com o padrão ético desejável no serviço público. Recomenda-se também a fixação de regras claras de conduta com a criação de instrumentos institucionais de divulgação e o acompanhamento da observância dessas regras, um maior envolvimento e comprometimento dos níveis hierárquicos superiores e a criação de uma rede interna de pessoas que trabalhará com a capacitação e divulgação de informações condizentes com a ética junto aos servidores da organização. Por fim, recomenda-se também o aprofundamento do estudo analisando outras variáveis e a replicação do mesmo em outras instituições a fim de realizar comparações.

\section{REFERÊNCIAS}

ABBAGNANO, N. Dicionário de Filosofia. 5. ed. São Paulo: Martins Fontes, 2007.

AMORIM, S. N. D. Ética na esfera pública: a busca de novas relações estado/sociedade. Revista do Serviço Público, v. 51, n. 2, p. 94-104, 2014.

BARDIN, L. Análise de conteúdo. 1. ed. São Paulo: Edições 70, 2011.

BIAGGIO, A. Lawrence Kohlberg: ética e educação moral. 2. ed. São Paulo: Moderna, 2006.

BRASIL. Lei 8.112, de 11 de Dezembro de 1990. Instituiu o Regime Jurídico dos Servidores Públicos Civis da União, das Autarquias e das Fundações Públicas Federais. [S.1.], 1990.

Decreto $n^{0} 1.171$, de 22 de junho de 1994. Código de Ética Profissional do Servidor Público Civil do Poder Executivo Federal. [S.1.], 1994.

Ministério da Educação. Instituto Federal do Ceará. Plano de desenvolvimento institucional (PDI) 2009-2013. [S.1.], 2013.

CARBONE, P. P. Cultura organizacional do setor público brasileiro: desenvolvendo uma metodologia de gerenciamento da cultura. Revista de Administração Pública, v. 34, n. 2, p. 133-144, 2000. 
ÉTICA E MORAL: HÁ DIFERENÇA ENTRE A TEORIA E A PRÁTICA?

CARNEIRO, J. G. P. O aprimoramento da conduta ética no serviço público federal. Revista do Serviço Público, v. 49, n. 3, p. 120-133, 1998.

FREITAS, A. B. Cultura organizacional e cultura brasileira. In: São Paulo: Atlas, 2006. cap. Traços Brasileiros para uma cultura organizacional., p. 38-54.

\section{LAKATOS, E. M.; MARCONI, M. A. Metodologia} do trabalho científico. 6. ed. São Paulo: Atlas, 2001

LICHT, R. H. Ética organizacional: busca de um modelo compreensivo para comportamentos morais. São Paulo, 1996.

. Uma análise da cultura ético-moral em organizações do abc paulista. In: Seminários Em Administração Fea-Usp. 10. ed. São Paulo: Anais, 2007. Disponível em: <http: //www.ead.fea.usp.br/semead/10semead/sistema/ resultado/trabalhosPDF/162.pdf>. Acesso em: 10 Junho 2014.

MACHADO, M. N. M. Cultura e imaginário organizacionais: Análise psicossociológica de algumas imagens. In: Pesquisas e Práticas Psicossociais. São João Del-Rei: UFSJ, 2008. Disponível em: <http://www.ufsj.edu.br/portal-repositorio/File/ revistalapip/volume3_n1/pdf/Machado.pdf> Acesso em: 10 Junho 2014.

MENDES, A. V. C.; JÚNIOR, H. de A.; LUZ, R. P. da; BORGES, C. Comissão de ética setorial: os desafios de fazer cumprir a ética na administração pública federal. Revista do Serviço Público, v. 61, n. 2, p. 137-156, 2010.

PATIAS, T. Z.; MINHO, C. S. V. As influências da cultura organizacional na prestação de serviços públicos. In: V Congresso CONSAD de Gestão Pública. Brasília: Anais, 2012. Disponível em: <www.escoladegoverno.pr.gov.br/arquivos/File/2013/ V.../035.pdf $>$. Acesso em: 10 Junho 2014.

PETRICK, J. A.; WAGLEY, R. A. Enhancing the responsible strategic management of organizations. Journal of Management Development, MCB UP Ltd, v. 11, n. 4, p. 57-72, 1992.

PIRES, J. C. d. S.; MACÊDO, K. B. Cultura organizacional em organizações públicas no brasil. Revista de Administração Pública, SciELO Brasil, v. 40, n. 1, p. 81-106, 2006.
SARAIVA, L. A. S. Cultura organizacional em ambiente burocrático. Revista de Administração Contemporânea, SciELO Brasil, v. 6, n. 1, p. 187-207, 2002.

Souza Filho, O. D. Ética individual \& ética profissional: princípios da razão feliz. Fortaleza: ABC Fortaleza, 1998.

SROUR, R. Poder, cultura e ética nas organizações: o desafio das formas de gestão. Rio de Janeiro: Elsevier Brasil, 2005.

TRIGUEIRO, E. S. O. Ética e comportamento moral dos servidores públicos: um estudo de caso no IFCE campus do Crato. Dissertação (Mestrado) Universidade Federal do Ceará, Fortaleza, 2012.

VASCONCELLOS, J. G. M. Recursos humanos e subjetividade. In: . Petrópolis: Vozes, 1995. cap. O coronelismo nas organizações: a gênese da gerência autoritária brasileira., p. 220-231. 